\title{
Improvement of Santa Terezinha Farm Productivity in the Egg Classification Sector, with Application to Automation: A Case Study
}

\author{
Rodrigo Chaves da Silva ${ }^{1}$, Raimundo Nonato Alves da Silva ${ }^{2}$, Yalle Aguiar da Silva ${ }^{3}$, Jéssica \\ Mylla Pereira Sousa ${ }^{4}$, Bruno da Silva Pinto ${ }^{5}$, Vanise dos Santos Rodrigues ${ }^{6}$
}

\author{
1,2,3,4,5,6 Centro Universitário do Norte (UNINORTE). Manaus-AM-Brasil.
}

Email: chavesdasilvarodrigo1994@gmail.com,raimundo.nonato.silva@gmail.com,yalleaguiar27@gmail.com, pintobruninho377@gmail.com, jessicampsousa@outlook.com, vanise_santosrodrigues@ hotmail.com

Received: February $17^{\text {th }}, 2017$

Accepted: April $27^{\text {th }}, 2017$

Published: June $30^{\text {th }}, 2017$

Copyright $@ 2016$ by authors and Institute of Technology Galileo of Amazon (ITEGAM). This work is licensed under the Creative Commons Attribution International License (CC BY 4.0).

http://creativecommons.org/lic enses/by/4.0/

\section{ABS TRACT:}

In order for a company to become competitive and stable in the market, it is advisable that it has the capacity to adapt with the constant improvements of technological evolution, making them able to meet the specifications and needs of the market. This case study aims to highlight the improvements of the Santa Terezinha Farm egg classification process, using automation as a tool, as well as to demonstrate the increase of the productive capacity and the efficiency of the previous process. The methodology applied in this work was an exploratory and descriptive research, which distributes in detail the process before and after the automation implantation in the egg classification line, having as procedures of data collection, interview with manager, and with a collaborator, besides of chronoanalysis. This study demonstrated the main benefits related to productivity, capacity and improvements with the implementation of automation. By proving that the company achieved a productivity increase of 128.5 prod./mens per hour compared to the previous process, where it was 7,5 prod./mens per hour, thus making the investment viable, and the process efficient. In this way, it can be concluded that the automation in the egg classification process has boosted the productivity increase, increasing the productive capacity, in the sense of attending to the customers' needs in a skilful way, without waste in the production, making the company stand out in the Market due to the application of the automation technique to increase productivity.

Keywords: Automation, Process Improvement; Increased productivity.

\begin{abstract}
RESUMO
A Para que uma empresa torne-se competitiva e estável no mercado, é aconselhável que a mesma tenha a capacidade de se adaptar com as constantes melhoras da evolução tecnológica, tornando-as capazes de atender as especificações e necessidades do mercado. Este estudo de caso tem como objetivo evidenciar as melhorias do processo de classificação dos ovos da Granja Santa Terezinha, utilizando a automação como ferramenta, além de comprovar o aumento da capacidade produtiva e a eficiência sobre o processo anterior. A metodologia aplicada neste trabalho foi de pesquisa exploratória e descritiva, que dista em detalhar o processo anterior e posterior a implantação da automação na linha de classificação de ovos, tendo como procedimentos de coletas de dados, entrevista com gerente, e com um colaborador, além de cronoanálises. Este estudo demonstrou os principais benefícios referente à produtividade, capacidade e as melhoras com a implantação da automação. Comprovando que a empresa obteve um aumento para 128,5 prod./Homens por hora na sua produtividade comparada ao processo anterior, onde o mesmo era de 7,5 prod./Homens por hora, tornando assim o investimento viável, e o processo eficiente. Desta forma pode se concluir que a automação no processo de classificação de ovos impulsionou o aumento da produtividade, ampliando a capacidade produtiva, no sentindo de atender a demanda dos clientes de forma hábil, sem desperdícios na produção, fazendo com que a empresa se destaque no mercado aviário pelo fato da aplicação da técnica de automação para o aumento da produtividade.
\end{abstract}

Palavras-Chave: educação, ciências agrárias, cisterna de produção 


\section{INTRODUÇÃO}

Em decorrência da globalização, houve um grande desenvolvimento tecnológico nas várias esferas industriais, e o setor aviário está se adaptando a essas evoluções.

Nesse campo industrial em nível mundial são existentes inúmeras granjas tendo cada uma sua diversificação, tanto em abates como em produções de ovos, independendo do tamanho do porte da empresa, todas tendem o mesmo objetivo, se manter no mercado e ter o processo de cada vez mais eficiente. A nível mundial os principais países produtores de ovos (unidades) são: China (482,974 bilhões), EUA (91,855 bilhões), Índia (63,500 bilhões), México (47,623), Japão (41,900 bilhões), Rússia (40,788 bilhões) e Brasil (40,731 bilhões), segundo [1].

No Brasil o número de produtores de ovos está em progressão com o passar dos anos, tornando o mercado cada vez mais competitivo de forma que as indústrias venham a crescer de maneira mais intensa, a fim de utilizar a automação como ferramenta principal de melhorias no processo produtivo. [2], cita que não existe mais espaço para amadoris mo na produção de aves e ovos no Brasil. Além do profissionalismo, a tecnologia faz parte do dia a dia das granjas, garantindo um produto seguro, de qualidade e com foco na sustentabilidade.

O Estado do Amazonas como incentivo do governo está se tornando uma grande força nesse nicho de mercado, contornando a crise e se tornando alto suficiente. De acordo com pesquis a [3]:

Com cerca de 80 granjas, a maioria instalada na região metropolitana de Manaus (AM), o setor avícola produtor de ovos tem crescido no estado do Amazonas nos últimos anos. Atualmente, são produzidos mensalmente 50 milhões de unidades, o que, estimam as autoridades agrícolas do estado, garantem a auto-suficiência da região [3].

$\mathrm{Na}$ rodovia AM-010, estão localizadas diversas granjas que atendem grande maioria do estado do Amazonas, chegando até em nível nacional de abastecimento. No Rio Preto da Eva, localizado no km 80 da rodovia AM-010, situa-se a granja Santa Terezinha, onde com o tempo se tornou um dos maiores produtores desse setor fabril.

Com o número extenso de empresas nesse segmento, e com grandes produções, as granjas têm a necessidade de se tornar mais sólida no mercado, de modo que sua produtividade aumente de maneira sucinta, onde torne as capazes de atender todos os seus clientes, pois a demanda é promissora nesse âmbito. A produtividade pode ser definida como a capacidade de produzir, partindo-se de certa quantidade de recursos, ou ainda o estado em que se dá a produção. (CONTADOR Apud [4]).

Por seguinte, surge a ferramenta da automação como alternativa de melhoria, com o intuito de somar com os produtores de ovos, a fim de tornar o processo eficiente, tornando maior a capacidade produtiva da empresa. Automação é todo o processo que realiza tarefas e atividades de forma autônoma ou que auxilia o homem em suas tarefas do dia a dia. ([14] Apud [5]).

Ressalta-se a influência dos elementos abordados, e pergunta-se: Será que o processo de classificação de ovos da Granja Santa Terezinha, tende a ser mais produtivo com a automatização?

$\mathrm{O}$ principal motivador deste estudo de caso foi à melhora do processo através da implantação de um sistema automatizado de clas sificação de ovos. Até então, o process so de classificação de ovos era considerado um "gargalo" na produção, pois em muitas vezes limitava o aumento da oferta desses produtos para o mercado.

Esse trabalho justifica-se a partir de uma necessidade do aumento da produtividade, consequentemente com ampliação da capacidade produtiva da empresa por meio da automação, com intuito de eliminar ocasiões de horas extras e custos inviáveis com a produção, proporcionando ao empreendedor ampliação da capacidade de produção, juntamente com o aumento da eficiência do processo de classificação de ovos da Granja Santa Terezinha.

\section{REVISÃO BIBLIOGRÁFICA}

\section{II.1 MELHORIA NO PROCESSO}

Melhorias devem ser constantes em busca da produtividade, e a qualidade do produto, de forma que com o passar dos anos este fator tornou-se primordial para o êxito de cada empresa.

Os processos podem ser melhorados de duas formas: a primeira consiste em melhorar o produto em si através da Engenharia do Valor. A segunda consiste em melhorar os métodos de fabricação do ponto de vista da Engenharia de Produção, que trata de procurar formas de otimizar a fabricação de determinado produto, (SHINGO Apud [6]).

\section{II.2 CLASSIFICAÇÃO DOS OVOS}

Entende-se pela simples designação ovos, os ovos de galinha em casca, sendo os demais acompanhados da indicação da espécie que procedem [7].

A classificação dos ovos são elementos do processo produtivo da empresa, onde se torna parte fundamental para atendimentos de especificações, tanto de legislações, qualidade e do cliente.

Em relação ao processamento de fabricação de ovos trata-se do procedimento de classificação, ovoscopia, lavagem, quebra de ovo, filtração, homogeneização, estabilização, pasteurização, resfriamento, congelamento, secagem e embalagem do produto final [7].

O Processo produtivo de ovos pode ser feitos de forma manual, ou automatizadas, tendo grandes influencias com o depender do tamanho da produção. Se a produção for baixa, no caso de um pequeno produtor, é aconselhável o processo ser executado de forma manual, mas se forem em grande escala, é prescindível ser realizada com a ajuda de uma automação no processo.

Segundo [8] poderá ser permitida a lavagem, ovoscopia e classificação manuais nos estabelecimentos que apenas recebeme manipulam ovos de produção própria, até o máximo de 3.000 (três mil) ovos/dia.

Quando é optável a forma manual de processamento é necessária ter como ponto de referência, assim como parâmetros, bandejas com crivos redondos de diferentes tamanhos que convêm para fazer a medição dos ovos, a fim de obter sua clas sificação.

Então, a fim de garantir uma maior acessibilidade durante o momento de comercialização e uma fiscalização mais controlada sobre os ovos de galinha, foram estabelecidas leis para que este produto fosse vendido em embalagens contendo 
informações referentes à cor da casca, classificação e tipificação [9].

Em questão sobre fatores dos ovos, como a da tonalidade da casca, o ovo deverá ter o nome de sua cor estabelecida na embalagem, por exemplo, "branco" ou "marrom". Sobre a Tipificação do produto, é relacionado sobre o peso onde a unidade do ovo se encaixa em cada categoria no critério de seleção por peso, onde são feitos com equipamentos industrializados.

De acordo com as informações da tabela 1 são decorrentes as especificações conforme com a sua tipificação e seus parâmetros em relação ao peso dos ovos, seguindo, contudo is so a conformidade ideal do produto. Por seguinte, o ovo tipo 1, nomeado de Jumbo ele tem um peso acima de 66 gramas, o tipo 2 nomeado de extratem o peso entre 60 gramas e 66 gramas. $\mathrm{O}$ ovo com a tipificação grande tem o mínimo de 55 gramas a 60 gramas. A tipificação de ovo médio tem o mínimo de 50 gramas a 55 gramas de acordo com a especificação, o tipo 5 que tem a sua nomenclatura pequena, tem no mínimo 45 gramas até 50 gramas. E o tipo 6, o ultimo da tipificação, mas não menos importante, nomeado de industrial tem um peso abaixo de 45 gramas.

Tabela 1: Tipificações dos ovos.

\section{TIPIFICAÇÃO DOS OVOS COMERCIAIS}

\begin{tabular}{l|l}
\hline Tipificação do Ovo & Parâmetros - Peso (g/unidade) \\
\hline Tipo 1 - Jumbo & $\geq 66$ \\
\hline Tipo 2 - Extra & Entre 60 - 66 \\
\hline Tipo 3 - Grande & Mínimo entre 55-60 \\
\hline Tipo 4 - Médio & Mínimo entre 50-55 \\
\hline Tipo 5 - Pequeno & Mínimo entre 45-50 \\
\hline Tipo 6 - Industrial & $<45$ \\
\hline
\end{tabular}

Fonte: [9], modificado por [10].

Neste contexto, o processo produtivo de classificação de ovos está em um ponto importantíssimo de forma que restringe quaisquer não conformidades do processo, e busca atingir de forma eficaz a qualidade através das legislações, tendo grande influência com o auxílio das automações que venham a contribuir com este meio.

\section{II.3 AUTOMAÇÃO}

Automação (do latim Automatus, que significa mover-se por si), vem ser um sistema automatizado com controles que verificam seu funcionamento próprio, realizando medições e introduzindo correções, sem a necessidade da interferência do homem [11]. As automações são técnicas utomáticas ou computadorizadas com o intuído de substituir ou diminuir a mão de obra [12].

A automação de processo que consiste em escolher, entre as diversas tecnologias disponíveis, maquinas, robôs ou software, assim a que apresentar melhor relação custo x benefício deverá ser escolhida [13].

Na metade do século XVIII a automação se evidenciou nas empresas da Inglaterra, onde para muitos era considerado o berço da automação. Foi nessa temporada que os processos produtivos tiveram um grande progresso, passando de artesanais para industrial, surgindo os equipamentos pioneiros para auxílio do trabalho dentro do âmbito produtivo [14].

[15] asseguram que o enorme crescimento no campo da automação industrial trouxe grande quantidade de máquinas automatizadas com recursos diversos.

O desenvolvimento da automação decorreu com o tempo, se deparando com diversas oportunidades para as organizações que no momento necessitavam de eficiência nos processos, além de velocidade na informação a fim de responder rapidamente a cada falha ou até mesmo detectar futuras falhas em seus sistemas [16].

A automação foi constantemente se evoluindo, trazendo inúmeros benefícios dentro do âmbito fabril, trazendo a cada progresso mais finalidades objetivas e produtivas, acarretando em aumento da velocidade na produção, além de otimizar recursos, transformando os processos muito mais eficientes, contudo isso deixando o processo mais produtivo, onde é o interesse primordial para as empresas futuristas do cotidiano.

\section{II.4 BALANCEAMENTO DE LINHAS}

As melhorias nos processos industriais devem ser sempre presente dentro das empresas, e o balanceamento de linha é um instrumento fundamental para análises de processos a ponto de evidenciar os gargalos viventes na produção, seja ela executada de forma manual ou automática. Em outras palavras o balanceamento de linha procura eliminar os desperdícios dentro da manufatura, e consequentemente tornar o processo mais estável, e mais efetivo.

As medições de tempo de ciclo são realizadas para avaliar a quantidade de trabalho aos colaboradores, de acordo

com esse fator, [17] afirma que o tempo de ciclo em função de dois elementos:

Em um sistema de produção, o tempo de ciclo é determinado pelas condições operativas da célula ou linha. Considerando-se uma célula ou linha com 'n' postos de trabalho, o tempo de ciclo é definido em função de dois elementos:

i. Tempos unitários de processamento em cada máquina/pos to (tempo-padrão);

ii. Número de trabalhadores na célula/linha.

Conforme [18], a realização da contagem do tempo de ciclo é obtida através da equação 1 :

\section{Tempo de Ciclo}

$$
=\frac{\text { tempo de produção }}{\text { quantidade produzida no tempo de produção }}
$$

Sendo assim, [19] descreve que "o tempo de ciclo é o tempo que decorre entre produtos finalizados, elementos de informação ou clientes obtidos no processo".

Balanceamento de linha é baseado no tempo de ciclo, que pode ser compreendido como a sequência dos postos de trabalho, tendo como intuito programar um método que vise uma distribuição mais eficiente das operações no chão de fábrica, sendo baseado no estudo de tempos, fluxo de materiais e redução de desperdício, envolvendo conceitos como o aumento da produtividade e otimização dos custos de fabricação [20].

O balanceamento de linhas de produção nos dias atuais assume relevância indubitável, principalmente pelas alterações no nível de produção industrial [21]. 
O balanceamento de linha é a atividade de distribuição de tarefas aos postos de trabalho, onde eles sejam impostos de forma justa e dividida. Sem esquecer que uma grandeza básica no balanceamento de linha é sua eficiência [22]. abaixo [23]:

Para balancear a linhas devem ser seguidos os passos

$>$ Estabelecer qual a sequência das tarefas, usando um diagrama de precedência;

$>$ Definir o tempo de ciclo necessário;

$>$ Definir o número mínimo teórico de estações de trabalho;

$>$ Escolher uma regra básica na qual as tarefas têm de ser alocadas às estações de trabalho e uma regra secundária para desempatar;

$>$ Atribuir as tarefas uma a uma à primeira estação até que a soma dos tempos da estação seja igual ao tempo de ciclo. Repetir o processo nas estações seguintes;

$>$ Avaliar a eficiência da linha.

O objetivo do balanceamento de linha de é elevar ao máximo a utilização dos postos de trabalho e, consequentemente, da mão-de-obra empregada, o balanceamento é necessário de forma a atender as necessidades distintas da organização ao produzir o que o mercado necessita. [24]. Sendo assim objetivo principal do balanceamento de linha é ter a maximização da eficiência ou a minimização do tempo ocioso [22].

\section{II.5 LAYOUT X ARRANJO FÍSICO}

Para [19] afirma que o "arranjo físico de uma operação ou processo é como seus recursos transformados são posicionados uns em relação aos outros e como as várias tarefas da operação serão alocadas a esses recursos transformadores." Já para [25] arranjo físico é a maneira de alocar as máquinas e equipamentos para otimizar o fluxo de produção de uma organização.

Conforme [26] "o arranjo físico de uma operação produtiva preocupa-se com o posicionamento físico dos recursos de transformação. Colocado de forma simples, definir o arranjo físico é decidir onde colocar todas as instalações, máquinas, equipamentos e pessoal da produção.”.

[26] cita cinco tipos de arranjo físico:

1. Arranjo físico posicional;

2. Arranjo físico por processo;

3. Arranjo físico celular;

4. Arranjo físico por produto;

5. Arranjos físicos mistos.

Afirma [25] que o arranjo físico é de estrema importância para a produtividade, pois os fluxos dos processos podem ser otimizados ou prejudicados em função da distribuição física de equipamentos. Sendo assim os objetivos conforme [19] de qualquer arranjo físico dependerão dos objetivos estratégicos de uma operação.

Segundo [27] o arranjo físico pode contribuir em:

$>$ Minimização dos custos de manuseio e movimentação interna de materiais;

> Utilizar o espaço físico disponível de forma eficiente;

$>$ Amparar o uso da mão de obra evitando que está se movimente de forma desnecessária;
$>$ Facilitar comunicação entre as pessoas envolvidas na operação quando adequado;

$>$ Reduzir o tempo de ciclo dentro da operação, garantindo fluxos mais linearizados, sempre possível e coerente com a estratégia;

$>$ Facilitar a entrada, saída e movimentação dos fluxos de pessoas e de materiais;

$>$ Facilitar a manutenção de recursos, garantido fácil acesso;

$>$ Facilitar o acesso visual as operações quando necessário;

$>$ Encorajar determinados fluxos.

Logo, o layout dentro de quaisquer empresas é de sumo valor pelo fato de evitar toda e qualquer condução desnecessária, além de dá o suporte necessário rumo às melhorias, e mesmo com mudanças, ou uso de automações, influencia diretamente na produtividade.

\section{II.6 CAPACIDADE PRODUTIVA}

Segundo [19] Cita que "a definição de capacidade de uma organização é o máximo de atividade de valor adicionado em determinado período de tempo que o processo pode realizar sob condições normais de operação."

Exara[15] Asseguram que em geral, capacidade de produção é a cadência máxima de produção de uma organização. A capacidade é o número máximo de produção de bens e serviços que podem ser produzidos em um intervalo de tempo [22].

Relata [19] que o "uso mais comum do termo capacidade é no sentido estático, físico, do volume fixo de um recipiente ou do espaço em um edifício.”. Já [27] menciona que a capacidade tem de ser vista como um potencial, um volume máximo possível de ser obtido, e não deve assim, ser confundida comos níveis de saída que a operação está produzindo em um certo período de tempo.

Então, a capacidade produtiva de uma organização é a produção máxima, onde é influenciada por fatores, onde devem ser controlados a fim de ter de ser maximização.

\section{II.7 PRODUTIVIDADE}

A produtividade se define na relação entre o que se produz e o que se deveria ser produzido. Com a necessidade de velocidade nos processos produtivos uma empresa mais produtiva não trabalha apenas buscando mais lucros, mas satisfação dos seus clientes e colaboradores. ([16].

A produtividade de acordo com [21] "é a relação entre o valor do produto e/ ou serviço produzido e o custo dos insumos para produzi-los.". Já [27] cita que "Produtividade é uma medida da eficiência com que os recursos de entrada de um sistema de agregação de valor são transformados em saídas. "

A produtividade mede a quantidade de trabalho do funcionário e a eficiência engloba a matéria prima, as máquinas, instalações e equipamentos [28]. Já [15] define que a produtividade significa a quantidade de produtos, ou serviços produzidos com os recursos utilizados. A produtividade num intervalo de tempo geralmente é medida através da equação 02 : 
Produtividade $=$

$\underline{\text { Quantidade de produtos ou serviços produzidos }}$

Quantidade de recursos utilizados

Assim, [15] também mencionam que a produtividade pode ser ampliada de diversas maneiras:

$>$ Aumentar a produção utilizando a mesma quantidade, ou quantidades menores de recursos;

$>$ Reduzir a quantidade de recursos utilizados enquanto a mesma produção é mantida ou aumentada;

$>$ Permitir que a quantidade de recursos utilizados se eleve contanto que a produção se ele mais;

$>$ Permitir que a produção decresça contanto que a quantidade de recursos utilizados decresça mais;

Para [29] existe dois elementos da produtividade:

> Produtividade Parcial: é a relação do produzido, medido de alguma forma, e o consumido de um dos recursos utilizados.

$>$ Produtividade Total: São todos os insumos utilizados para produzir o produto.

Quando se aumenta a produtividade, se provoca um melhor aproveitamento dos insumos, além de diminuir os custos de produção, ou dos serviços prestados [22].

Em busca por competitividade a empresa deve apresentar-se mais produtiva e eficiente que seus concorrentes, assim sua sobrevivência está diretamente ligada à sua capacidade de ser competitiva (Burmeister Apud [13]).

Conforme as bases referenciais acima, para controlar e fazer uma menção da produtividade precisa-se ter embasamentos na eficiência, tanto da linha, como de todo arranjo físico, onde é a capacidade de alcançar objetivos com o mínimo de insumos possíveis, consequentemente otimizando tempo e recursos.

\section{MATERIAIS E MÉTODOS}

\section{III.1 APRESENTAÇÃO DA EMPRESA}

A empresa Granja Santa Terezinha é uma das pioneiras no setor aviário na região metropolitana de Manaus. Localizada no $\mathrm{km} 85$ da rodovia AM 010, tiveram o início de suas atividades na década de 80 em âmbito familiar, somente com criação de frangos de corte, com o passar dos anos e com o mudar da economia, mudou sua estratégia de produção, e começaram trabalhos com a criação de galinhas de posturas, em outras palavras, galinhas destinadas a produções de ovos.

Com o encaminhar dos anos, a Granja Santa Terezinha evoluiu seus planos de produção, aumentando sua capacidade produtiva e investindo em tecnologias, iniciando seu processo de maturidade de seu produto, mantendo-se estável no mercado, e hoje em dia abastecendo todo o município de Rio Preto da Eva e seus arredores, por conta da fácil logística na rodovia AM 010.

A Coleta de informações foi atribuída no setor de classificação dos ovos, onde houve um minucioso estudo de tempo, analisando o processo anterior e o pos terior a implantação da automação, além disso, foram executadas entrevistas informais com o gerente e com um colaborador experiente no setor.

O quadro 02 informa como é organizada, e como pode ser medida a produção de ovo na granja Santa Terezinha em busca dos estudos.
Tabela 2: Quantidades de ovos.

\begin{tabular}{c|c}
\hline Forma de ovos & Caixa de ovos \\
\hline 30 unidades & 360 unidades \\
\hline
\end{tabular}

Fonte: Autores, (2016).

A cronoanálise foi o instrumento fundamental para a obtenção dos estudos de tempos, de acordo com [24] a cronoanálise é uma ferramenta utilizada para avaliação e o registro dos tempos gastos na área de produção da empresa, que visa identificar uma sequência lógica do fluxo operacional mais apropriado e eficiente ao trabalho. Com este instrumento também é possível verificar a existência de gargalos na produção.

Nesta pesquisa foi empregado o uso de um cronometro, da folha de verificação (Tabela 3 ) e anotações com um grande nível de atenção.

Tabela 3: folha de verificação.

\begin{tabular}{|c|c|c|c|c|}
\hline \multicolumn{5}{|c|}{ FOLHA DE VERIFICAÇÃO } \\
\hline \multicolumn{3}{|c|}{$\begin{array}{l}\text { EMPRESA: Granja Santa } \\
\text { Terezinha }\end{array}$} & DATA: & 1 \\
\hline \multicolumn{3}{|c|}{$\begin{array}{l}\text { PROCESSO: Classificação } \\
\text { de ovos }\end{array}$} & \multicolumn{2}{|l|}{ HORA } \\
\hline \multicolumn{5}{|c|}{ OBS: } \\
\hline $\begin{array}{l}\text { Número do } \\
\text { processo }\end{array}$ & Etapas & Tempo (s) & Quantidade de ovos & Colaborador \\
\hline \multicolumn{5}{|l|}{01} \\
\hline \multicolumn{5}{|l|}{02} \\
\hline \multicolumn{5}{|l|}{03} \\
\hline \multicolumn{5}{|l|}{04} \\
\hline \multicolumn{5}{|l|}{05} \\
\hline \multicolumn{5}{|l|}{06} \\
\hline \multicolumn{5}{|l|}{07} \\
\hline \multicolumn{5}{|l|}{08} \\
\hline $\mathrm{TO}^{-1}$ & & & & \\
\hline
\end{tabular}

Fonte: Autores, (2016).

\section{III.2 DESCRIÇÃO DO PROCESSO ANTERIOR}

A Granja Santa Terezinha tinha seu processo anterior de forma muita das vezes manual, operada de forma intensa com a mão de obra por parte dos colaboradores. No setor de classificação dos ovos, onde são selecionados os ovos, não era diferente, abrangendo de um número excessivo de colaboradores no setor.

Descreve [19] que fluxogramas ou mapas de processos são usados para obter o melhor entendimento detalhado antes do melhoramento, além de tornar claras as áreas de melhoramento.

A figura 1 explana o fluxograma como funcionava de forma manual o processo de classificação de ovos na granja.

O processo se inicia com a chegada dos ovos no setor de classificação, logo após ocorre uma separação dos ovos através do seu estado visual, estando limpo em devida situação segue em diante o processo, se não é direcionado a uma área de higienização. Em seguida os ovos são direcionados a uma fase de classificação, tendo uma parametrização través de o seu tamanho devido sua execução ser feita de forma manual, e logo em diante era embalado de acordo com sua especificação. 


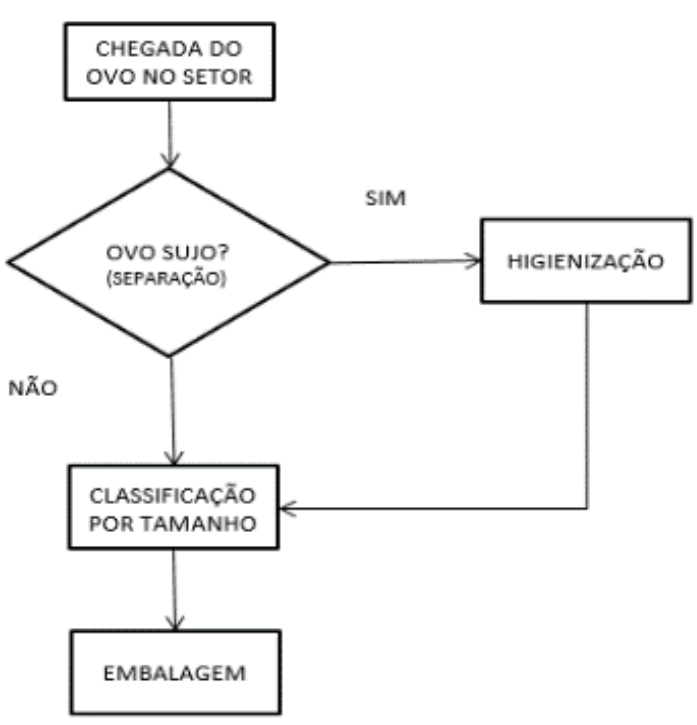

Figura 1: Fluxograma: Processo produtivo antigo. Fonte: Autores, (2016).

\section{III.3 FASES DO PROCESSO DE CLASSIFICAÇÃO DOS OVOS MANUAL}

Após a chegada do produto no setor, ocorre a seleção dos ovos limpos dos sujos, onde a figura 2 representa a fase de higienização dos ovos, onde é feita a lavagens para atingir sua limpeza de forma eficaz. Sem esquecer que as atividades acima eram efetuadas por dois colaboradores, cada um realizando cada função.

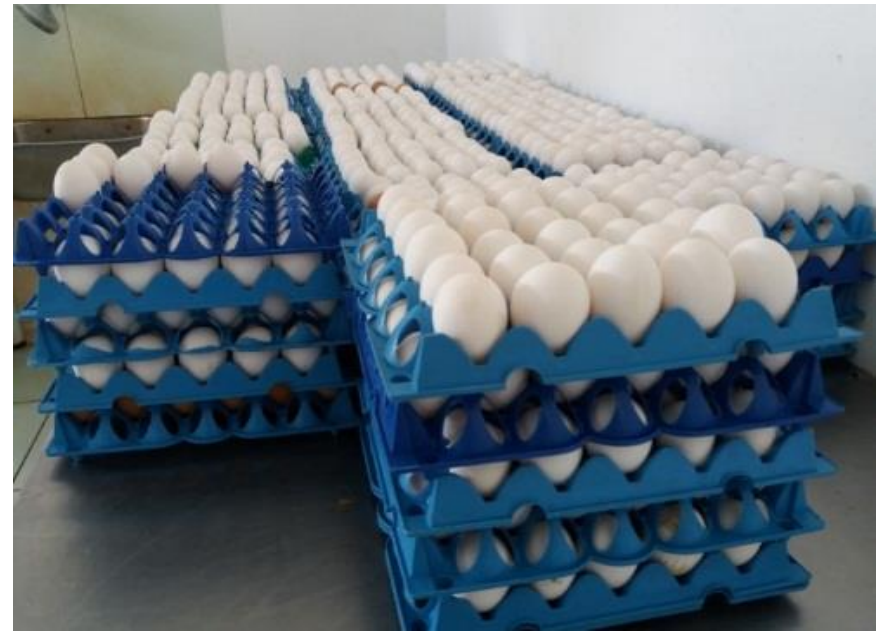

Figura 2: Higienização dos ovos.

Fonte: Autores, (2016).

Após a triagem e a higienização dos ovos, é executada a fase de classificação, onde era considerada a restrição de capacidade do processo. A fase era realizada por três colaboradores onde mesmo assim demandava um tempo consideravelmente grande para realização da atividade. A Figura 3 apresenta as bandejas de classificação manual, onde eram selecionados os ovos de acordo com seu tamanho e sua cor, variando de tipificação de acordo com a circunferência da forma.

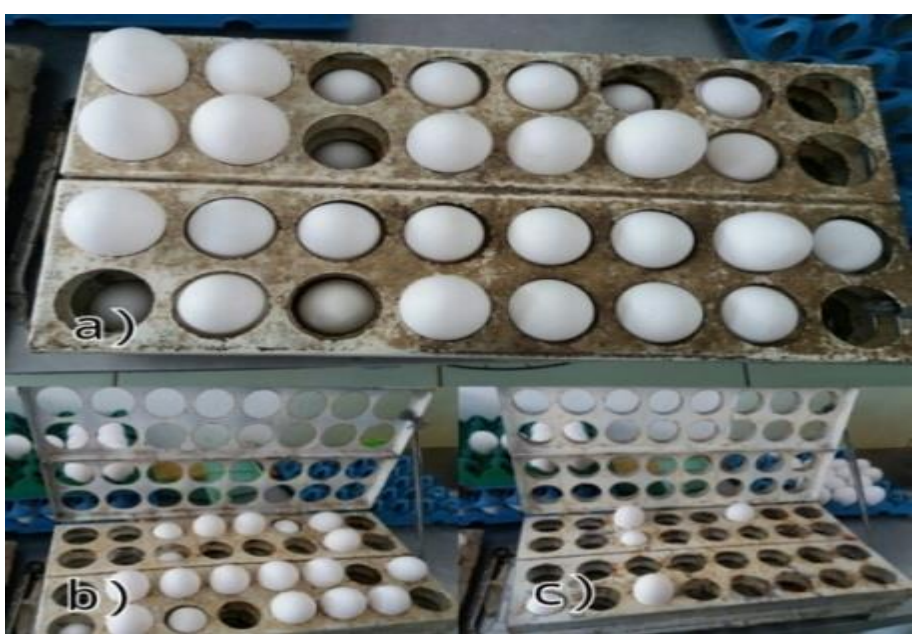

Figura 3: Classificação dos ovos.

Fonte: Autores, (2016).

A última atividade do processo de forma manual é a embalagem do produto acabado, a figura 4 demonstra a embalagem final do produto, de acordo com suas classificações e especificações tanto do cliente quanto da legislação.

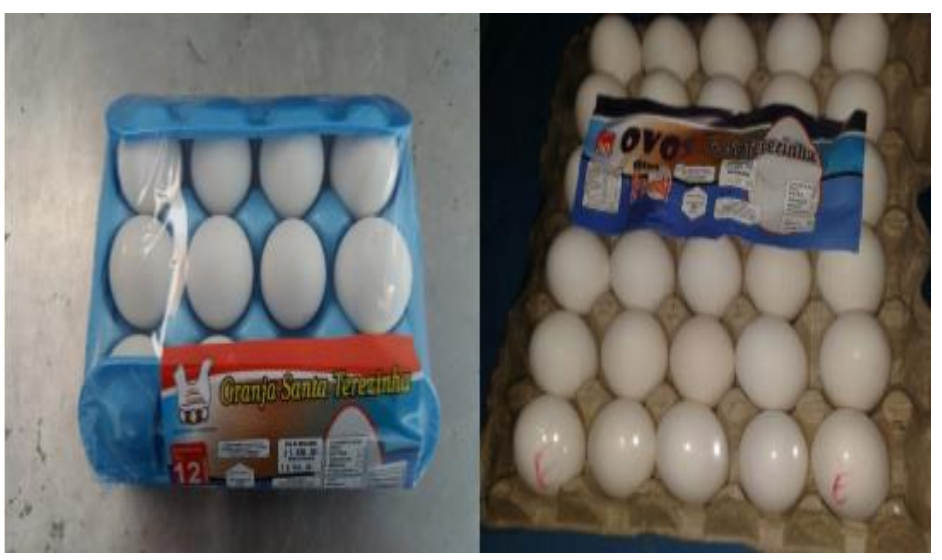

Figura 4: Embalagem dos ovos.

Fonte: Autores, (2016).

\section{III.4 DESCRIÇÃO DO PROCESSO ATUAL}

Com o avanço da globalização, o aumento de novas tecnologias se tornou necessidade de as empresas investirem em tecnologia para ocorrer melhorias em seu processo produtivo. A Granja Santa Terezinha com o andar dos anos mudou seu processo por conta disso, a fim de seu processo ocorresse a melhoria ideal ao processo. A automatização implantada revolucionou o processo, tornando-o mais produtivo, utilizando menos recursos que de forma manual.

A figura 5 informa o processo produtivo de classificação de ovos atual da empresa granja Santa Terezinha. Inicia-se semelhante ao processo manual, mas com a triagem dos ovos de forma mais rigorosa, com intuído de ser processados primeiro os ovos totalmente limpos. Logo em seguida são introduzidos os ovos na máquina com uso do sugador, que é um instrumento facilitador da automação, em diante o processo percorre em direção ao processo de polimento dos ovos. Depois de passar pelo polimento, chega na parte dos ovos cópia e segue em rumo das balanças de precisão, e chegando ao final nas bandejas de préembalagem. 


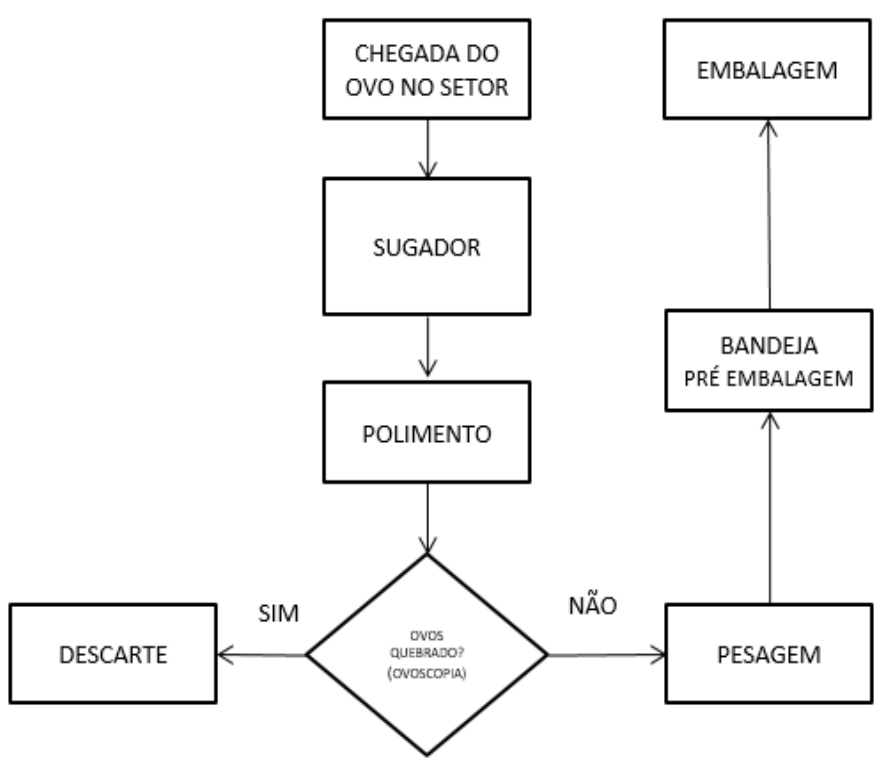

Figura 5: Fluxograma: Processo automatizado Fonte: Autores, (2016).

\section{III.4.1 FASES DO PROCESSO DE CLASSIFICAÇÃO DOS OVOS SEMIAUTOMÁTICA.}

Após implantação da automação, treinamentos e ajustes foram designadas fases no processo, mesmo sendo automatizada, até então algumas atividades tendo influência da mão de obra e outras atividades totalmente automáticas. A figura 6 representa a primeira atividade do processo automatizado, que é designado por um colaborador, onde tem a função de introduzir os ovos na esteira, com o auxílio do sugador, que é uma bomba a vácuo que recebe comandos de forma onde facilita a introdução do produto no processo.

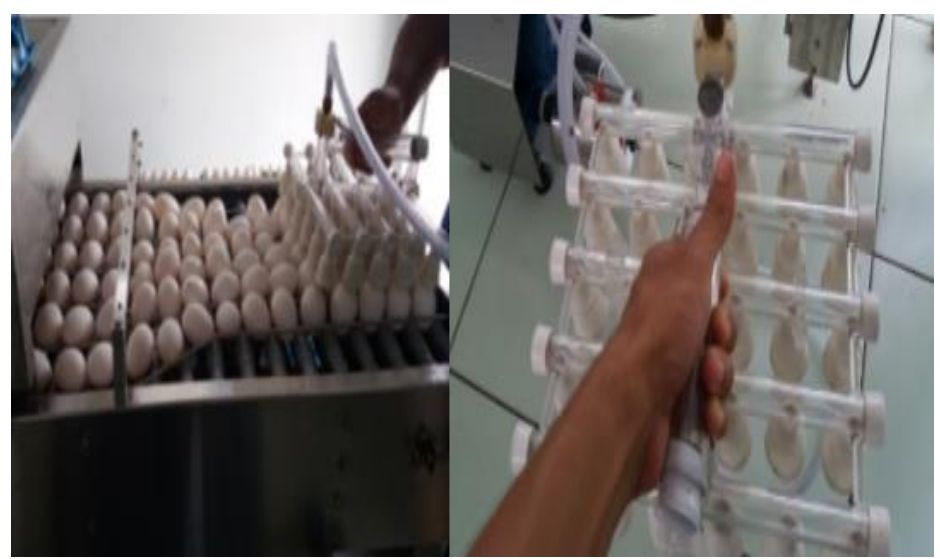

Figura 6:Introdução do ovo no processo (sugador).

Fonte: Autores, (2016)

Prosseguindo o processo, logo após a introdução do produto na esteira é realizado o polimento dos ovos, onde é retirada qualquer impureza visível no produto, e com o objetivo de deixar a casca do ovo em bom estado visual. A figura 7 exibe esta atividade que é realizada de forma automática sem intervenção humana.

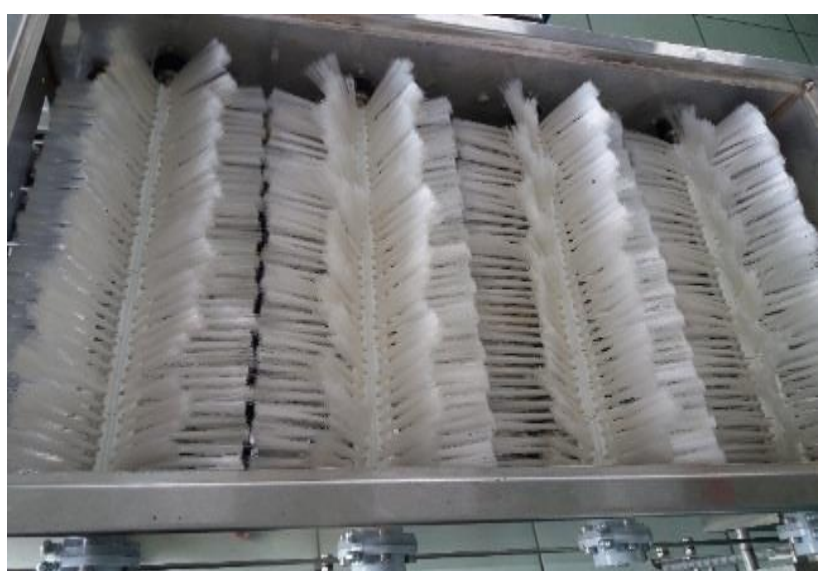

Figura 7: Polimento.

Fonte: Autores, (2016).

A seguir, a figura 8 representa a atividade nomeada de ovos cópia, que tem como função eliminar os produtos não conformes, que fogem da qualidade, sendo assimque apresentam algum defeito. Essa atividade é efetuada por um colaborador onde o mesmo é responsável de retirar do processo ovos que tenham anormalidades como: trincas, cascas não conformes, sendo assim a presença de qualquer a irregularidades no produto.

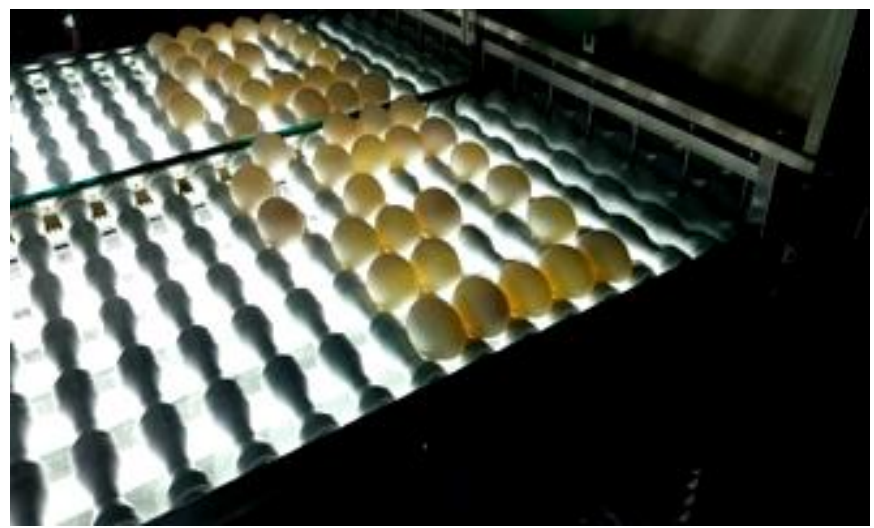

Figura 8: Ovoscopia.

Fonte: Autores, (2016)

Enfim chega a parte da pesagem eletrônica, onde são pesados os ovos em pequenas balanças de precisão e por seguinte são classificados os ovos de forma automática de acordo com sua tipificação de forma exata, notando que essa fase é

completamente automática, sem influência da mão de obra na atividade conforme a figura 9.

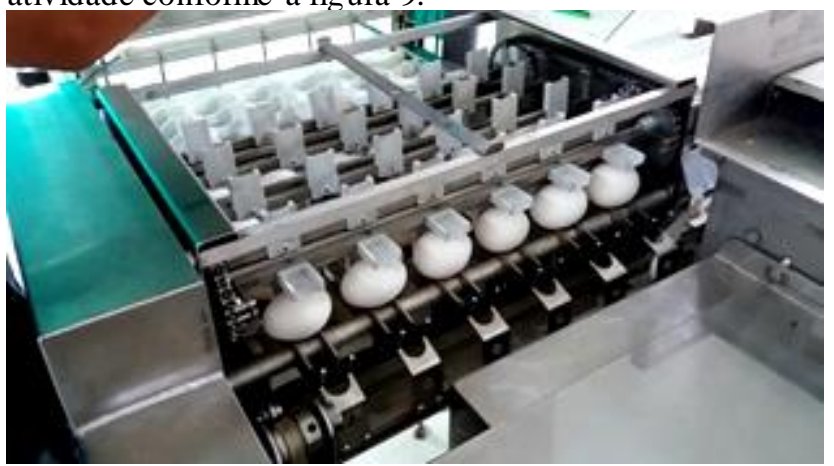

Figura 9: Pesagem Eletrônica.

Fonte: Autores, (2016). 
Empós o produto ser classificado, ele é direcionado as bandejas de pré-embalagem, de acordo com sua tipificação, tendo cada parte, um recebimento de tipo de classificação diferente, sendo um facilitador na pré-embalagem dos dois colaboradores do posto. A figura 10 mostra a atividade, onde são pré-embalados os ovos de acordo com sua especificação, seguindo após disso rumo ao seu armazenamento.

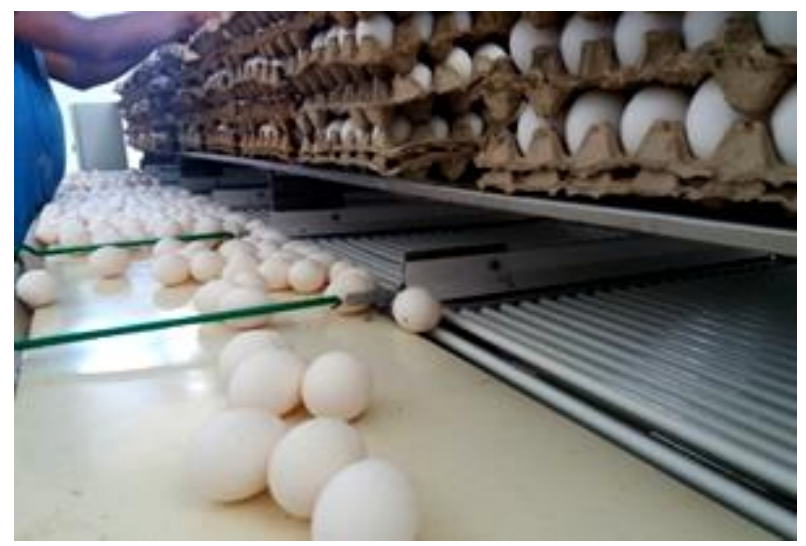

Figura 9 - Bandejas de Pré-embalagem.

Fonte: Autores, (2016).

\section{RESULTADOS E DISCUSSÕES}

Depois de levantamentos das atividades no processo, e de estudos de tempo antes e após a implantação da máquina, tendo em vista oportunidades de desenvolvimento do processo, notou-se que houve o aumento da produtividade, envolvendo a capacidade produtiva da empresa, através da implantação desta automação que influenciou grandemente no layout e no tempo do processo.

No tabela 4, observa-se a coleta de dados sobre o estudo de tempo, e balanceamento de atividades na linha antiga, antes mesmo da implantação da máquina. A produção é medida por formas de ovos, onde se totalizam 30 unidades de ovos em cada forma, então as análises foram executadas deste modo. Ao mesmo tempo nota-se que são quatro atividades no processo, começando pela separação dos ovos limpos e sujos, sendo executada por um funcionário tendo como finalidade produzir 0,75 unidades por minuto. Logo em seguida a segunda atividade é a lavagem dos ovos sujos tendo 0,5 unidades de formas por minuto empregando dois colaboradores na atividade. Na terceira atividade tendo descrição de classificação pelo fato de classificar os ovos de acordo com o tamanho de sua circunferência, onde demandava maior parte dos colaboradores e exercendo o mínimo de produtividade no processo com apenas 0,33 formas de ovos por minuto. Na quarta e última atividade do processo onde é feita a embalagem do produto era exercida a produção de 1 forma de ovo por minuto onde demandava 1 funcionário.

Deste modo, sabe-se que a média da demanda diária é 360 unidades de formas de ovo, onde esse número não era atingido em um turno normal de trabalho, pois os dados acima demonstram que 6 colaboradores executavam as atividades tendo uma produção diária de um pouco mais de 337 formas de ovos por turno trabalhado. Com base nestes dados, percebe-se que era de necessidade o uso de horas extras para obter a demanda diária em um dia normal de trabalho.
Tabela 4: Balanceamento da linha antiga.

\begin{tabular}{|c|c|c|c|c|c|c|}
\hline \multicolumn{7}{|c|}{ LINHA ANTIGA } \\
\hline Número & Descricão & Atividade & segiunid & nnid/min & Colaboradores & $\begin{array}{l}\text { unid. } \\
\text { total }\end{array}$ \\
\hline 1 & SEPARACCĀO & A & 80 & 0,75 & 1 & 0,75 \\
\hline 2 & LAVAGEM & B & 60 & 1 & 1 & 1 \\
\hline 3 & CLASSIFICACAÄO & C & 180 & 0,33 & 3 & 1 \\
\hline 4 & EMBALAGEM & D & 60 & 1,00 & 1 & 1 \\
\hline \multicolumn{7}{|c|}{ DEMANDA DIARIA } \\
\hline 360 & \multirow[t]{2}{*}{ Unidades } & \multicolumn{2}{|c|}{$\begin{array}{c}\text { Total de } \\
\text { colaboradores }\end{array}$} & Produção/hora & \multicolumn{2}{|c|}{ Produçäa/turno } \\
\hline 7,5 & & \multicolumn{2}{|c|}{6} & 45 & \multicolumn{2}{|c|}{337.5} \\
\hline
\end{tabular}

Fonte: Autores, (2016).

A partir da conclusão da implantação, e o funcionamento da máquina com força total, foram executados a coleta dos dados do quadro seguinte. A partir das apreciações do novo processo foram constatadas novas atividades e algumas que passaram a ser automatizadas.

Tabela 5: Balanceamento após Implantação.

\begin{tabular}{|c|c|c|c|c|c|c|}
\hline \multicolumn{7}{|c|}{ LINHA IMPLANTANDO A MÁQUUNA } \\
\hline NUMERO & DESCRIC̣ÃO & ATIVIDADE & SEG/UNID & UNID/MIN & COLABORADORES & $\begin{array}{l}\text { Unid. } \\
\text { Total }\end{array}$ \\
\hline 1 & SULGADOR & A & 7 & 8,6 & 1 & 8,6 \\
\hline 2 & POLIMENTO & $B$ & 7 & 8,6 & 0 & 0,0 \\
\hline 3 & OVOSCOPIA & $\mathrm{C}$ & 7 & 8,6 & 1 & 8,6 \\
\hline 4 & PESAGEM & D & 7 & 8,6 & 0 & 0,0 \\
\hline 5 & BANDEJA & E & 14 & 4,3 & 2 & 8,6 \\
\hline \multicolumn{2}{|c|}{ DEMANDA DIÁRIA } & & & & & \\
\hline 504 & Unidades & \multicolumn{2}{|c|}{ Total de colaboradores } & Produção/hora & \multicolumn{2}{|c|}{ Produção/turno } \\
\hline 7,5 & Horas & \multicolumn{2}{|c|}{4} & 514,3 & \multicolumn{2}{|l|}{3857.1} \\
\hline
\end{tabular}

Fonte: Autores, (2016).

De acordo com o tabela 5, a primeira atividade onde é nomeada como sugador tem uma produtividade de 8,6 unidades de formas por minuto utilizando apenas um colaborador. $\mathrm{Na}$ segunda atividade tendo a função de polir os ovos, tem a capacidade de produzir 8,6 unidades de formas por minuto, eliminando a utilização da mão de obra humana, pois ela é uma atividade totalmente automatizada. $\mathrm{Na}$ atividade 3 , a ovos cópia emprega apenas a mão de obra de um colaborador tendo 8,6 unidades de forma por minuto. A atividade 4, a pesagem dos ovos através de pequenas balanças eletrônicas de precisão exerce uma produção neste posto de trabalho de 8,6 unidades de formas por minuto, e sendo de configuração automatizada sem o impacto de mão de obra humana. E na última atividade, não menos importante, exerce 4,3 unidades de formas de ovos por minuto, utilizando neste posto de trabalho 2 colaboradores.

Contudo analisa-se que o investimento em automação foi o que atendeu com maior eficiência a empresa, pois aumentou de forma significativa a capacidade produtiva da granja, precisamente de um pouco mais de 514 unidades de formas por hora, e 3857 unidades formas por turno trabalhado, mesmo sabendo que para atingir demanda diária da granja basta executar apenas uma hora de trabalho no processo, e sem esquecer de ter como alternativa o domínio de direcionar 2 colaboradores a outros 
postos de trabalho, especificamente para o setor administrativo da empresa.

A figura 11 demonstra o novo layout de linha da empresa, que mesmo com a mudança não houve alteração no tipo de layout, mas onde se constata a subtração do número de colaboradores, de seis para quatro funcionários no processo, dando o interesse em direcionar es ses colaboradores subtraídos da linha a novos postos de trabalho, contudo isso tornando o processo muito mais eficiente e produtivo.

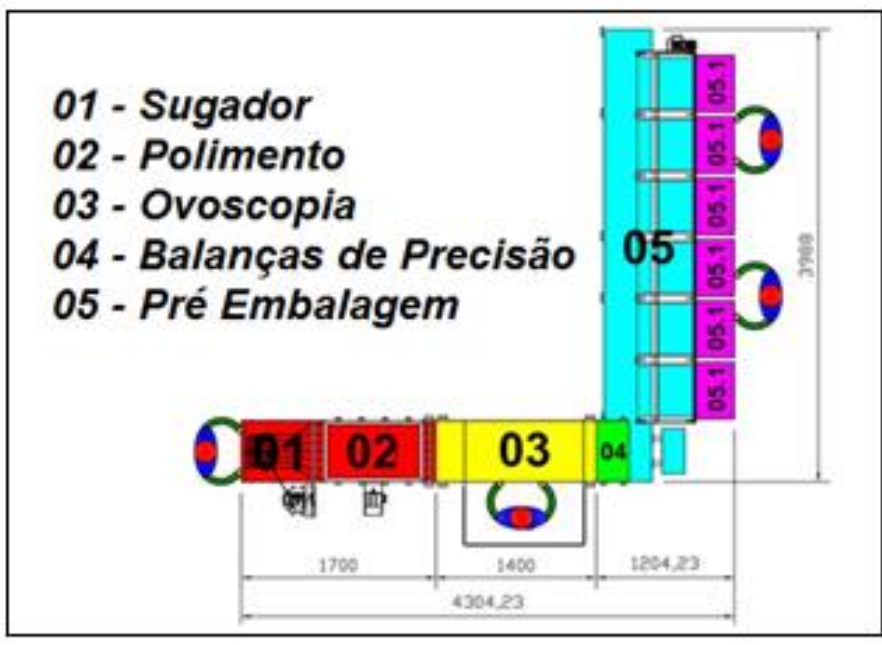

Figura 10 :Layout do processo após implantação.

Fonte: Adaptado de [31].

Os cálculos de capacidade foram executados conforme a equações 3 e 4 :

Informações com base na linha antiga, capacidade do processo manual.

Capacidade Produtiva $=\frac{Q t . d e \text { Produtos produzidos no turno }}{\text { Tempo total de produção }}$

(3)

Capacidade Produtiva $=\frac{337,5}{7,5}$

Capacidade Produtiva $=\mathbf{4 5}$ formas de ovos por hora

Informações com a linha após a implantação, Capacidade do Processo automatizado.

Capacidade Produtiva

$=\frac{Q t . d e \text { Produtos produzidos no turno }}{\text { Tempo total de produção }}$

Capacidade Produtiva $=\frac{3857}{7,5}$

Capacidade Produtiva

$$
=\mathbf{5 1 4} \text { formas de ovos por hora }
$$

Com bases nos cálculos, e na comprovação do aumento da capacidade, cabe glosar o trabalho de [30] que fizeram um estudo, onde apresentaram um aumento de $121 \%$ na sua capacidade produtiva, eliminando desperdícios, utilizando da melhor forma seus funcionários, e tornando o processo analisado mais eficiente. Já [31] com uso intenso da tecnologia, especificamente com a implantação de uma automação no processo, conseguiu obter um aumento da capacidade produtiva de $42,9 \%$, e passou atender a demanda sem restrições, sem esquecer do aumento de sua produtividade em relação a mão de obra.

O gráfico da figura 11 explana a capacidade produtiva da empresa nos aspectos abordados.

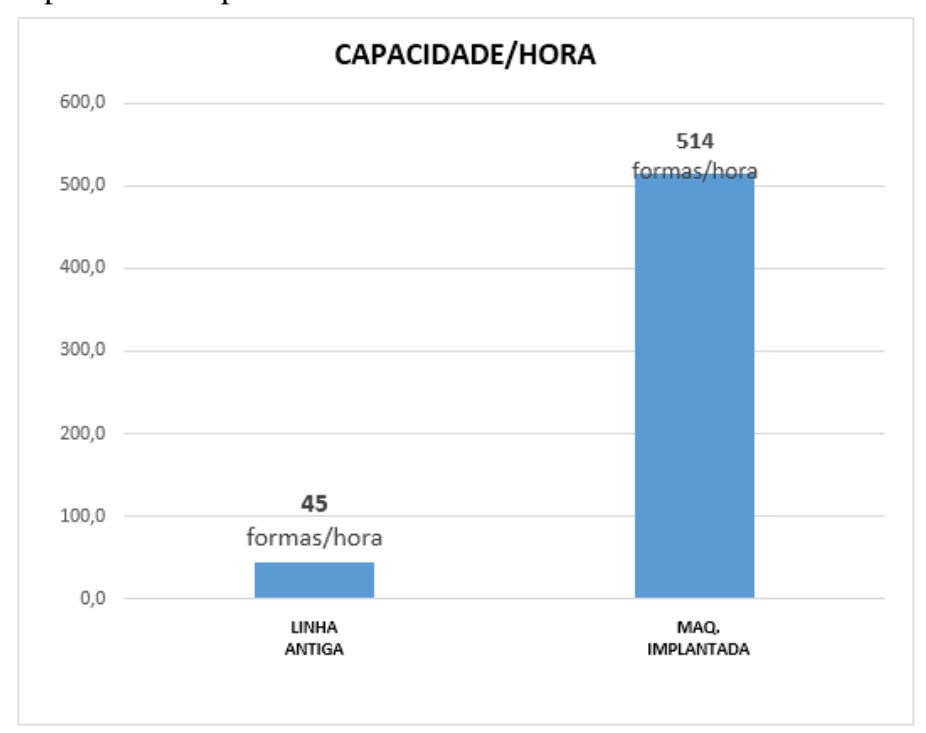

Figura 11: Gráfico de capacidade do processo.

Fonte: Autores, (2016).

De forma que a linha antiga tinha uma capacidade produtiva de 45 formas de ovos por hora, totalizando 1350 ovos processados por hora. Com a implantação da máquina teve um aumento considerável na capacidade produtiva da empresa, obtendo um resultado de 514 formas de ovos por hora, totalizando a capacidade mínima da máquina que é de 15420 ovos por hora.

Os cálculos de produtividade foram adimplidos da equação 4.

$$
\begin{aligned}
& \frac{\text { Produtividade }}{\text { Hora }} \\
& =\frac{Q t \cdot \text { de produtos produzidos }}{Q t \cdot \text { de Recursos utilizados }}
\end{aligned}
$$

Informações com base na linha antiga.

$$
\begin{aligned}
& \text { Produtividade } / \text { Hora }=\frac{45 \text { formas }}{6 \text { Homens }} \\
& \text { Produtividade } / \text { Hora }=7,5 \text { formas } / \text { Homens }
\end{aligned}
$$

Informações com a linha posterior, com a implantação: 
Produtividade $/$ Hora $=\frac{Q t . \text { de produtos produzidos }}{Q t . \text { de Recursos utilizados }}$

Produtividade $/$ Hora $=\frac{514 \text { formas }}{4 \text { Homens }}$

Produtividade

$$
\text { Hora }
$$

O gráfico da figura 12 nos informa o índice de produtividade nos âmbitos abordados, como na linha antiga, e depois da implantação da máquina classificadora de ovos. Onde o gráfico expõe que na linha antiga obtinha uma produtividade de 7,5 por hora trabalhada. Com a implantação da máquina passou-se para uma produtividade de 128,5 por hora. Tornando sem dúvidas o melhor caminho tomado rumo à produtividade.

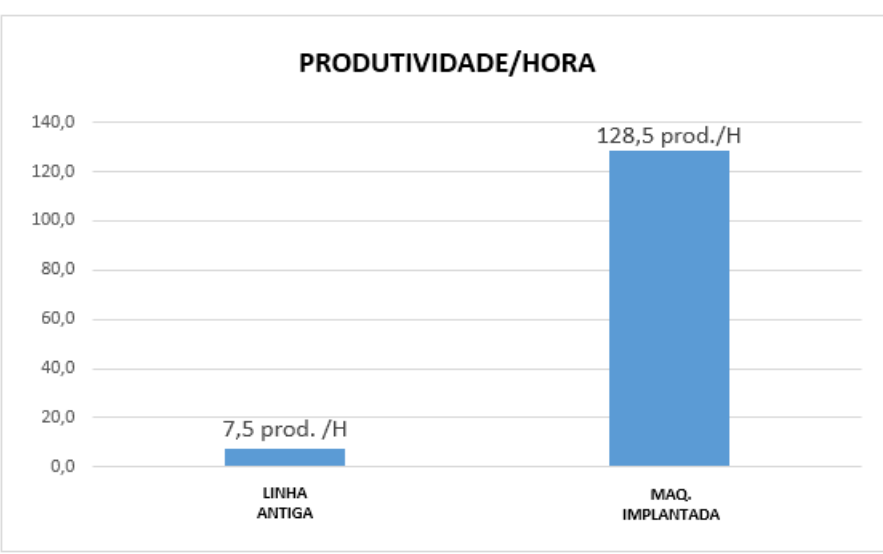

Figura 12: Gráfico de Produtividade do processo.

Fonte: Autores, (2016).

O processo manual de classificação de ovos era muito restrito, então se tornava um processo problemático por conta da baixa produtividade, e logo se dificultava a competência de atender as especificações e os clientes, tendo assim o uso amplo de horas extras e alto nível de desperdícios. Com o manuseio da automação o processo deixou de ser problemático para ser efetivo, ampliando a capacidade produtiva, e a produtividade do setor, além de eliminar gargalos dentro do processo produtivo de ovos. Conforme os resultados obtidos, percebem-se as diferenças dos processos discutidos neste trabalho, logo, comprova-se que foram de profunda aceitação o novo método de classificação de ovos da granja, onde o processo anterior se tornava escasso nas esferas de capacidade e produtividade, pois restrições se mantinham presentes no setor.

Portanto, tendo em vistas todos os dados abordados, a máquina de classificação de ovos revolucionou esse processo crítico da empresa, suprindo todas as necessidades que foram ressaltadas, transformando o processo muito mais eficiente e produtivo, e tornando a Granja Santa Terezinha mais competitiva nesse mercado, capaz de atender todos os clientes.

\section{CONCLUSÃO}

O estudo abordou importância da produtividade com o auxílio da tecnologia, tendo em vistas que a automação pode contribuir com o processo de forma efetiva, aumentando a produtividade. Este trabalho demonstrou o aumento da capacidade produtiva, que no proces so anterior tinha a capacidade de produzir 45 formas de ovos por hora e passou a produzir como uso da automação 514 formas de ovos por hora, tendo um aumento significante em relação ao processo anterior de $1142,2 \%$.

A comprovação de sua eficiência vem por caráter da produtividade, então sendo assim, a linha antiga que obtinha eficiência de $750 \%$ por hora, com a utilização da automação, passou-se a ter $12850 \%$ por hora, sem esquecer que houve influência direta na sua mão de obra na linha, reduzindo-a.

Com isto, as melhoras no processo são em relação a produtividade, a capacidade produtiva, e a eficiência do processo automático sobre o processo manual, além de haver uma melhora em questão do tempo, e o uso mais consistente dos colaboradores do setor.

O valor do investimento de implantação do sistema semiautomático de classificação de ovos na Granja Santa Terezinha, foi de R\$ 112.250,00 (Cento e dose mil, duzentos e cinquenta reais).

Sendo assim de caráter evolutivo, este estudo abre um leque de possibilidades de trabalhos futuros, então se sugere trabalhos relacionados à implantação de novos anexos automatizados dentro do processo, em outras palavras, novas automações dando continuidade do processo produtivo dos ovos, eliminando desperdícios e a possibilidades de surgimentos de novos gargalos, assim como, pensa-se em novas estratégias de vendas, buscando novos mercados. Com is to indica-se trabalhos relacionados à implementação do processo de ovos pasteurizados, deste modo formulando novos produtos, sem esquecer-se de aprofundar a inovação tecnológica no ramo. Conclui-se que a automação é uma ferramenta fundamental dentro dos setores fabris, pois tem o intuito de oferecer benefícios que somam em prol das empresas, fazendo que o mercado tenha tendência de se tornar aquecido e competitivo.

Portanto, este estudo de caso acredita que o mesmo venha a contribuir com as situações e as pessoas relacionadas da área, onde deseje utilizar o conhecimento adquirido na sua prática, executando essa alternativa rumo a efetividade.

\section{AGRADECIMENTOS}

Ao grupo de pesquisa do Centro Universitário do Norte (UNINORTE) pelo apoio ao desenvolvimento da pesquisa.

\section{REFERÊNCIAS}

[1] Silva, Roberto de Andrade. Análises de Conjuntura e Agropecuária Avicultura de Postura - Secretaria de Estado da Agricultura e do Abastecimento (SEAB). Disponivel: $<$ http://www.agricultura.pr.gov.br/arquivos/File/deral/P rognosticos/avicultura_postura_2012_13.pdf>. 2012/2013 - Acesso em: 22 de set. 2016

[2] Pulici, Carlos. Revista Avicultura Brasil - União Brasileira de Avicultura (UBABEF). $\mathrm{N}^{\circ} 1$ - São Paulo, SP. 2012. Disponível em: http://abpa-br.com.br. Acesso em: Acesso em: 30 de out. 2016.

[3] Avicultura Amazonense. Portal a Hora do Ovo (2012) Disponível em:http://www.ahoradoovo.com.br/no-mundo-doovo/notícias. Acesso em: 05 de set. 2016. 
[4] Garcia, P. L. P.; Barros, J. G. M, Panhoca, L. Implantação de um programa de melhoria da produtividade, 2007. Revista Brasileira de Gestão e desenvolvimento Regional. Disponível em < http://www.rbgdr.net/032007/artigo4.pdf> Acesso em: 30 de out. 2016.

[5] Amaral, Rodrigo. Projeto de Implantação de um Sistema de Automação para Silos de Armazenamento de Matéria Prima. Trabalho de Conclusão de Curso, 2012. Disponível em: < http://www.em.ufop.br/cecau/monografias/2012 > .Acesso em: 08 de Nov. 2016.

[6] Gerlach, G. Proposta de melhoria de Layout visando a otimização do processo produtivo de uma empresa de pequeno porte, 2013. Disponível em:< http://www.fahor.com.br/EngPro/2013/Pro Gustavo.pdf> acesso em: 30 out. 2016.

[7] BRASIL. Portaria $\mathrm{n}^{\circ}$ 01, de 21 de fevereiro de 1990. Ministério da Agricultura e do Abastecimento. Secretaria de Inspeção de Produto Animal. Divisão de Inspeção de Carnes e Derivados - DICAR. Normas Gerais de Inspeção de Ovos e Derivados. Diário Oficial da República Federativa do Brasil, Brasília, DF, n. 44, p. 4321, 6 de mar. 1990. Seção 1. Disponível em:

http://www.avisite.com.br/legis lacao/anexos/PORTARIA.>

Acesso em: 30 out. 2016.

[8] Miró. Renato L. L. Coordenador do SIP/POA. Publicado em Diário Oficial dia 06/06/1998, págs. 12,13,14, e 15. Curitiba, 26 de março de 1.998 . Disponível em : $\langle$ http://www.adapar.pr.gov.br $>$ Acesso em: 13 de out. 2016.

[9] BRASIL. Resolução CIPOA no 005 de 19 de novembro de 1991. Trata da aprovação de padrões de identidade e qualidade de produtos lácteos e de ovos do Ministério da Agricultura, Pecuária e Abastecimento. Diário Oficial República Federativa do Brasil, no 78, 1991. Brasília / DF. Disponível em : < http://www.agricultura.gov.brl $>$. Acesso em: 01 de nov. 2016.

[10] Moraes, I.A.; MANO, S.; BAPTISTA, R.F. Análise da rotulagem de ovos comercializados na cidade do Rio de Janeiro - Brasil. Revista Brasileira de Ciência Veterinária, v.14, n.1, p.7-11, 2007. Disponível em: < http://www.uff.br > acesso em 01 de nov. 2016.

[11] Holanda, AURÉlIO BUARQUE DE. Novo dicionário da língua portuguesa. 12a.impressão. Rio de Janeiro: Nova Fronteira, 1975. p. 163.

[12] Szezerbick, A. S. HENRY FORD: A visão inovadora de um homem do início do século XX. Artigo Centro Federal de Educação Tecnológica do Paraná - PR, 2004.

[13] Pinto, J. R. C.; NUNES, F. L.; VIERO, C. F. Avaliação dos ganhos de Produtividade e redução de Custos pela automação de processos em uma empresa calçadista: Um estudo de caso. Revista Espacios. Vol. 36. № 16, 2015. Pág. 6. Disponível em: < http://www.revistaespacios.com/a15v36n 16/15361606.html >

Acesso em: 01 de nov. de 2016
[14] Rosario, J. M. Automação Industrial. São Paulo: Baraúna, 2009.

[15] Gaither, Norman. Frazier, Greg - Administração da Produção e Operações. $8^{a}$ Ed. São Paulo: Cengage e Learning, 2002.

[16] Diedrich. H. Utilização de Conceitos do Sistema Toyota de Produção na Melhoria de um Processo de Fabricação de Calçados, 168F, 2002 Dissertação (Mestrado em Engenharia) Universidade Federal do Rio Grande do Sul.

[17] Alvarez, R. dos R.; JR, J. A. V. A. Takt-Time: Conceitos e Contextualização dentro do Sistema Toyota de Produção., p7, Gestão \& Produção, 2001.

[18] Martins, Petrônio G. Administração da Produção/ Petrônio G. Martins, Fernando Piero Laugeni. $-2^{\text {a }}$ ed. Ver. Aum. E atual. São Paulo: Saraiva, 2005.

[19] Slack, Nigel. Administração da produção/ Nigel Slack, Stuart Chambers, Robert Johnston; Tradução Henrique Luiz Correa. - $3^{\text {a }}$ Ed. - São Paulo: Atlas, 2009.

[20] Tubino, D. F. Planejamento e controle da produção: teoria e prática. São Paulo: Atlas, 2007.

[21] Diniz, N.O. S.; CALIFE, N. F. S. Cronoanálise e Balanceamento de linha de montagem: Estudo de caso em uma montadora de veículos. XXXV Encontro Nacional de Engenharia de Produção. ENERGEP, 2015. Disponível em: $<$ http://www.abepro.org.br $>$. Acesso em 22 de set. 2016.

[22] Moreira, Daniel Augusto - Administração da produção e operações. $2^{\text {a }}$ Ed. Re. E ampl. São Paulo: Cengage e Learning, 2013.

[23] Junior, A. S. Balanceamento de Linha: Estudo de caso Para Otimização de Recursos de uma linha de Produção. Trabalho de Conclusão de Curso, 2012. Disponível em: $<$ http://repositorio.roca.utfpr.edu.br $>$. Acesso em 01 de out. 2016.

[24] Rocha, J. A. V. da, Navarro, A. A importância da capacidade produtiva e cronoanálise para empresas do polo moveleiro de Ubá. In: SAEPRO: Simpósio Acadêmico de Engenharia de Produção, IX. 2014, Viçosa.

[25] Paranhos filho, Moacyr. Gestão da Produção Industrial. Curitiba. Ed. Ibpex, 2007.

[26] Slack, Nigel, Chambers, Stuart, Johnston, Robert Administração da Produção: ATLAS, $2^{\text {a }}$ edição de 2002

[27] Corrêa, Henrique L. Administração de produção e operações: manufatura e serviços: uma abordagem estratégica/ Henrique L. Corrêa; Carlos A. Corrêa. $1^{\mathrm{a}}$ Ed. Reimp. - São Paulo: Atlas, 2009.

[28] Santos, L.; Cardoso, J.;Reis, L.; Moraes, J.M; Silva, A. A melhoria de processo através da implantação de técnicas da engenharia em uma empresa do ramo alimentício. V 
Congresso Brasileiro de Engenharia de Produção. COMBREPO, 2015. Disponivel em: $<$ www.aprepro.org.br/conbrepro/2015> Acesso em: 01 de Nov. 2016.

[29] Martins, Petrônio G. Administração da Produção fácil/Petrônio G. Martins, Fernando Piero Laugeni. - São Paulo: Saraiva, 2012.

[30] Souza, J. S.; Balieiro, R. T.; Oliveira, P. H. S.; Mesquita, W. G.; Brum, R. P. Castro, P. A.;Inácio, F.

[31] Carvalho, Vianey S.; GUARNIERE, Alexson B.; SCHEIN, Samuel. Automação para aumento da produção em empresa do setor alimentício: Ume estudo de caso. XXXII Encontro Nacional de Engenharia de Produção - ENERGEP, 2012.

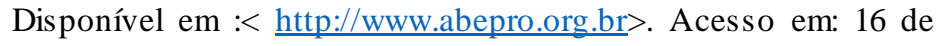
nov. 2016. 